\title{
Stress System and Social Interaction Focusing on the Sexual Pathway
}

\author{
Fahimeh Ghahvehchi-Hosseini ${ }^{1}$, Hedayat Sahraei ${ }^{2}$ and Boshra Hatef (iD ${ }^{2,}{ }^{*}$ \\ ${ }^{1}$ Behavioral Science Research Center, Life Style Institue, Baqiyatallah University of Medical Science, Tehran, Iran \\ ${ }^{2}$ Neuroscience Research Center, Baqiyatallah University of Medical Science, Tehran, Iran \\ "Corresponding author: Neuroscience Research Center, Baqiyatallah University of Medical Science, Tehran, Iran. Email: boshrahatef@bmsu.ac.ir
}

Received 2020 August 19; Revised 2020 October 11; Accepted 2020 December 13.

Keywords: Sexual Privacy, Social Interaction, Stress System, Sex Difference

\section{Dear editor,}

Privacy in the workplace as a social problem has recently become a significant issue; however, it did not attract much attention in the past (1). Heterosexual relationships that take place at work are inherently involuntary and unequal since men generally have more power, income, and possibilities than women, and women are often under harassment in the romances of the workplace $(1,2)$. In addition to harassment, romantic relationships at work can be led to declining productivity of organizations and team working as well as increasing some negative moral traits such as gossip, jealousy, and suspicion due to favoritism $(1,2)$. Then it is a serious question that whether sexual privacy is established between men and women. Sexual privacy can be referred to as wide matters such as type of the relationship between two genders, the appearance, and their body coverage, local culture, and religion but this paper focus on the global meaning of sexual privacy. In history, there has always been a change in the type of coverage and privacy that is the indication of the historical periods of each land (3). Therefore, the type of coverage and the scope of privacy are considered societies' common indicators of their culture and social relationships. In fact, it is difficult to change a society's behavior as it is already accepted as a custom (3). The scope of the sexual privacy of men and women can be discussed as a biological subject, in addition to the cultural, economic, and religious requirements so that the ultimate choice of society is an integration of all these factors. Then this letter proposed a neurobiological insight to social interaction of men and women as an opinion article. The different responses of genders to sexual stimulation and attractive- ness are discussed.

Studies have shown that men's brain response while looking at attractive women's faces is significantly higher compared to looking at neutral or non-attractive faces. It is indicated that men's brains are activated more when looking at the beautiful and attractive faces of women. On the other hand, no differences have been observed in women's brain responses with regard to the attraction of men (4). However, other studies demonstrated an increase in testosterone and cortisol in women who watched attractive men and men who looked at attractive women $(5,6)$. Thus the attractiveness is significantly related to sexual hormones (6). According to the previous findings, the activity of emotional centers of the brain (particularly the amygdala, hypothalamus, thalamus, insula, orbital frontal, and cingulate cortex) is more in men than women when they are watching sexual, provocative images or movies. However, there is no difference between the self-reporting of sexual stimulation between two genders $(7,8)$. While women are more making imaginations of sexual stimulation, men tend to pay more attention to different parts of sexual visual stimuli (9). Following a pleasant stimulus, including visual, auditory, olfactory, tactile senses or a combination of them, many parts of the brain involved in the reward system such as the amygdala, ventral tegmentum area, and nucleus accumbens are activated, and a high level of dopamine is released (10) since the brain is always seeking to repeat the experiences having more pleasure (11). For example, a man's brain who encountered a sexually attractive woman experiences more pleasure subconsciously and reinforces him involuntarily to end up looking more at the attractive and sexy women.

It is under controversy that the accessory pathway of 
the olfactory system controls the sexual and social behaviors of the living being in humans. Pheromones are chemical compounds influenced by sex steroids, leading to triggering a series of sex-related behaviors by affecting the amygdala, hypothalamus, and hypothalamicpituitary-gonad axes (12). Sexual pheromones may also act as an additional factor that can influence the dynamics of human sexual communication (13). Therefore, it might be considered that exposure to the sexual chemo-signals alters sexual cues when the physical distance is not enough to remove the effect of pheromones. It is probably true to say that the reason behind some Islamic instructions, regarding hijab and the observance of some issues, especially communication with distance between women and men, might be related to the connection of pheromones to the receptors, such that the pheromones of male and female hormone activate the sexual arousal when binding to their receptors in the opposite sex, not to the same sex or those who share the same mother or father. In other words, they do not activate the same familiar genetic structures (14).

Failure to observe privacy may occur when a man communicates with a gender, especially in women, who is attractive by her clothing style or behavior and increases sexual desire in another gender. Following these triggers, the pathway of the medial part of the amygdala to the anterior part of the hypothalamus, particularly preoptic nucleus (these two parts have special sexual cells, which are involved in the unconscious sexual control), is activated. The hypothalamus-pituitary-gonad (HPG) axis generates sexual desires. Sexual hormones that are released from gonads have positive feedback on the amygdala and HPG axis. Notably, this effect is diminished and eliminated after sexual satisfaction and orgasm as the level of hormones decreased (15). The visual and olfactory stimulations directly excite the sexual cells in the medial amygdala. The size and extension of the group of neurons in men are greater than in women. In addition, its relationship with the higher cognitive centers is also different between the two genders. Even the amount of inputs and outputs are different in men and women (16-18). The repeated failure in sexual satisfaction can cause the amygdala to remain in high activity and trigger the activity of another system means the stress system. In this pathway, the paraventricular nucleus (PVN) of the hypothalamus is activated by the activation of the central amygdala. Afterward, the hypothalamus-pituitaryadrenal (HPA) axis and other outputs from PVN are also activated (15). The cortisol hormone, as the output of the
HPA axis, has a negative feedback on the HPG axis. While the testosterone or estradiol, as the output of the HPG axis, increases the activity of the amygdala and HPA axis (Figure 1). Then, the activity of HPA gradually increases until the level of gonadal hormones is diminished (19). Subsequently, chronic stress decreases the HPG activity and reduces reproductively and sexual arousal. In addition, a high level of cortisol, after a long period of time, increases the activity and connectivity of the amygdala, as a center of emotion, while decreases the activity and connectivity of the hippocampus, as a center of memory, and the prefrontal cortex, as a center of cognition, with other regions, cause brain aging (20). Impairments associated with longterm activation of the sympathetic systems such as gastrointestinal, neurological, cardiovascular, metabolic, and immunological disorders are also predicted (21). Therefore, it is suggested that sexual stimulation with a sense of pleasure initially gives rise to positive emotions in the individual, but if the right conditions of sexual satisfaction in the long term are not provided, the stress persists and causes irreparable harm to the health of the individual and society such as workplace harassment and chronic stress.

\section{Footnotes}

Authors' Contribution: $\mathrm{BH}$ and HS designed and drafted the manuscript. BH and FG reviewed and collected the related articles. All authors contributed to writing and revising the manuscript.

Conflict of Interests: The authors declare that there is no conflict of interest.

Funding/Support: There is no funding or support.

\section{References}

1. Williams CL, Giuffre PA, Dellinger K. Sexuality in the workplace: Organizational control, sexual harassment, and the pursuit of pleasure. Annual Review of Sociology. 1999;25(1):73-93. doi: 10.1146/annurev.soc.25.1.73.

2. Chan-Serafin S, Teo L, Minbashian A, Cheng D, Wang L. The perils of dating your boss: The role of hierarchical workplace romance and sex on evaluators' career advancement decisions for lower status romance participants. J Soc Pers Relat. 2016;34(3):309-33. doi 10.1177/0265407516635285.

3. Izadkhasti Z, Izadkhasti M. [Background and structure of covering women from ancient times up to Islam]. women and culture. 2012;4(13):71-84. Persian.

4. van Hooff JC, Crawford $\mathrm{H}$, van Vugt $\mathrm{M}$. The wandering mind of men: ERP evidence for gender differences in attention bias towards attractive opposite sex faces. Soc Cogn Affect Neurosci. 2011;6(4):47785. doi: 10.1093/scan/nsq066. [PubMed: 20601424]. [PubMed Central: PMC3150857]. 
5. Stern J, Karastoyanova K, Kandrik M, Torrance JS, Hahn A, Holzleitner IJ, et al. Are sexual desire and sociosexual orientation related to men's salivary steroid hormones? Adapt. Hum. Behav. Physiol. 2020;6(4):44766. doi: 10.31234/osf.io/42t6e.

6. Rinn R, Kirsch F, Agthe M, Niesta Kayser D. Fertility as a cue for attractiveness in homo- and heterosexual men. Personality and Individual Differences. 2020;166:110171. doi:10.1016/j.paid.2020.110171.

7. Hamann S. Sex differences in the responses of the human amygdala. Neuroscientist. 2005;11(4):288-93. doi: 10.1177/1073858404271981. [PubMed: 16061516].

8. Rupp HA, Wallen K. Sex differences in response to visual sexual stimuli: a review. Arch Sex Behav. 2008;37(2):206-18. doi: 10.1007/s10508007-9217-9. [PubMed: 17668311]. [PubMed Central: PMC2739403].

9. Carvalho J, Gomes AQ, Laja P, Oliveira C, Vilarinho S, Janssen E, et al. Gender differences in sexual arousal and affective responses to erotica: the effects of type of film and fantasy instructions. Arch Sex Behav. 2013;42(6):1011-9. doi: 10.1007/s10508-013-0076-2. [PubMed: 23519591].

10. Liang $X$, Zebrowitz LA, Zhang Y. Neural activation in the "reward circuit" shows a nonlinear response to facial attractiveness. Soc Neurosci. 2010;5(3):320-34. doi: 10.1080/17470911003619916. [PubMed: 20221946]. [PubMed Central: PMC2885490].

11. Esch T, Stefano GB. The neurobiology of pleasure, reward processes, addiction and their health implications. Neuro Endocrinol Lett. 2004;25(4):235-51.

12. Trotier D. Vomeronasal organ and human pheromones. Eur Ann Otorhinolaryngol Head Neck Dis. 2011;128(4):184-90. doi: 10.1016/j.anorl.2010.11.008. [PubMed: 21377439].

13. Wisman A, Shrira I. Sexual chemosignals: Evidence that men process olfactory signals of women's sexual arousal. Arch Sex Behav. 2020;49(5):1505-16. doi: 10.1007/s10508-019-01588-8. [PubMed: 32026223]. [PubMed Central: PMC7299914].
14. Henningsson S, Hovey D, Vass K, Walum H, Sandnabba K, Santtila P, et al. A missense polymorphism in the putative pheromone receptor gene VN1R1 is associated with sociosexual behavior. Transl Psychiatry. 2017;7(4). e1102. doi: 10.1038/tp.2017.70. [PubMed: 28440809]. [PubMed Central: PMC5416707].

15. Toufexis D, Rivarola MA, Lara H, Viau V. Stress and the reproductive axis. J Neuroendocrinol. 2014;26(9):573-86. doi: 10.1111/jne.12179. [PubMed: 25040027]. [PubMed Central: PMC4166402].

16. Kilpatrick LA, Zald DH, Pardo JV, Cahill LF. Sex-related differences in amygdala functional connectivity during resting conditions. Neuroimage. 2006;30(2):452-61. doi: 10.1016/j.neuroimage.2005.09.065. [PubMed: 16326115].

17. Mitsushima D, Yamada K, Takase K, Funabashi T, Kimura F. Sex differences in the basolateral amygdala: the extracellular levels of serotonin and dopamine, and their responses to restraint stress in rats. Eur J Neurosci. 2006;24(11):3245-54. doi: 10.1111/j.14609568.2006.05214.x. [PubMed: 17156385].

18. Squire L, Berg D, Bloom FE, Du Lac S, Ghosh A, Spitzer NC. Fundamental neuroscience. Academic Press; 2012.

19. Dalooei JR, Sahraei H, Meftahi GH, Khosravi M, Bahari Z, Hatef B, et al. Temporary amygdala inhibition reduces stress effects in female mice. J Adv Res. 2016;7(5):643-9. doi: 10.1016/j.jare.2016.06.008. [PubMed: 27489731]. [PubMed Central: PMC4950119].

20. McEwen BS, Bowles NP, Gray JD, Hill MN, Hunter RG, Karatsoreos IN, et al. Mechanisms of stress in the brain. Nat Neurosci. 2015;18(10):135363. doi: 10.1038/nn.4086. [PubMed: 26404710]. [PubMed Central: PMC4933289].

21. Yaribeygi H, Panahi Y, Sahraei H, Johnston TP, Sahebkar A. The impact of stress on body function: A review. EXCLI Journal. 2017;16:1057. doi: 10.17179/excli2017-480. 


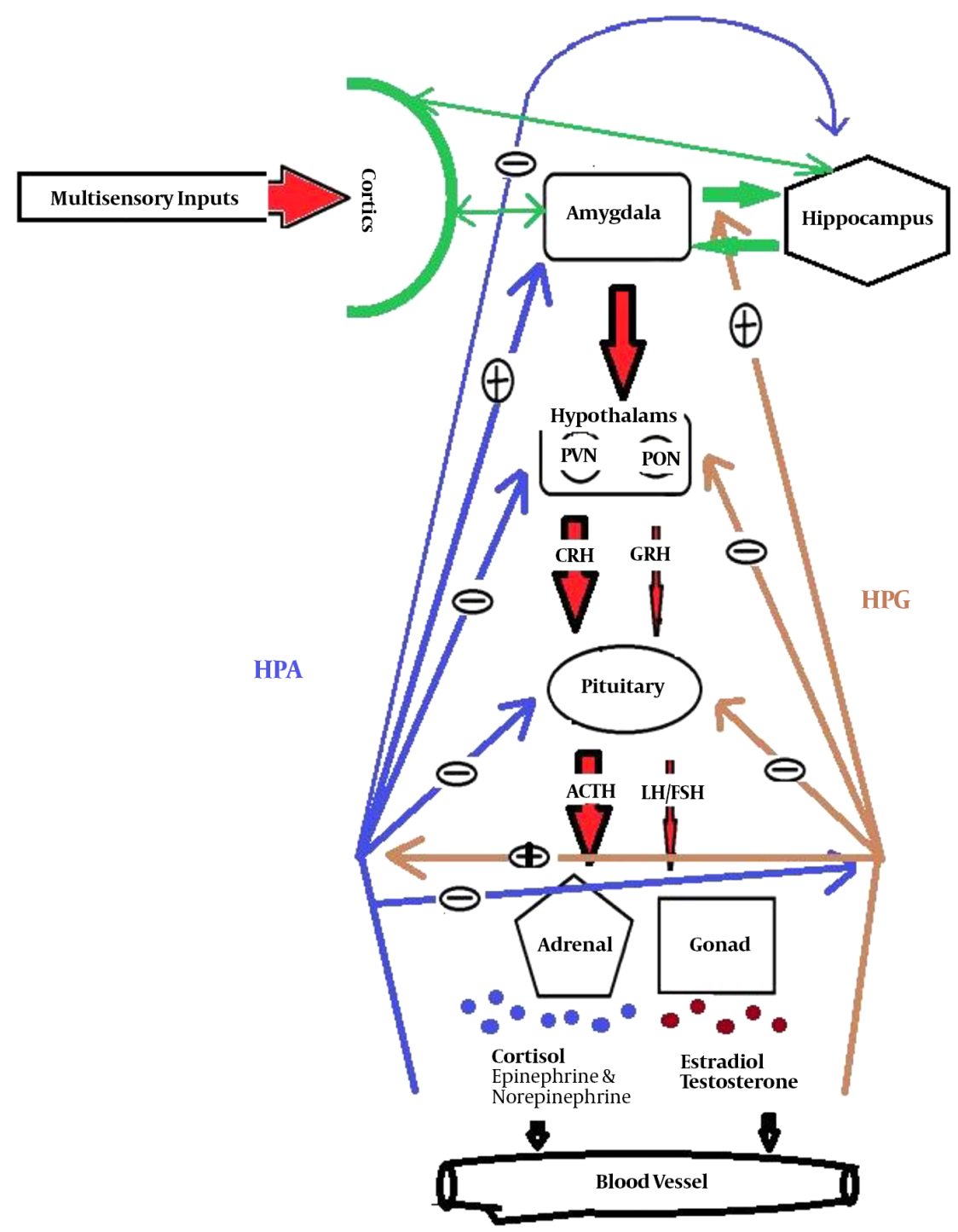

Figure 1. Stress and sexual pathway. The amygdala can be activated by multisensory input from several cortices and activates two axes of HPA for stress and HPG for sexual arousal. The preoptic nucleus (PON) of the hypothalamus is responsible for releasing the gonadotropin-releasing hormone (GRH), which activates the pituitary gland. It releases the $\mathrm{LH} / \mathrm{FSH}$ sex hormones to the bloodstream that go to the gonads. Gonads release testosterone in men and estradiol steroid hormones in women, having different effects on the activity and sexual cycle. The paraventricular nucleus (PVN) of the hypothalamus, which is responsible for the release of the glucocorticoid-releasing hormone $(\mathrm{CRH})$, affects several parts of the brain. In the HPA, it promotes the pituitary gland to releases adrenocorticotropic hormone (ACTH). ACTH, in the blood, affects the adrenal gland and increases the secretion of cortisol, epinephrine, and norepinephrine from the parts of the gland into the bloodstream. These hormones, as negative feedback, reduce the activity of the pituitary and hypothalamus, as well as the activity of the HPG; meanwhile, they increase the activity of the amygdala. Cortisol has a negative feedback on HPG, while sexual hormones have positive feedback on the HPA axis. 